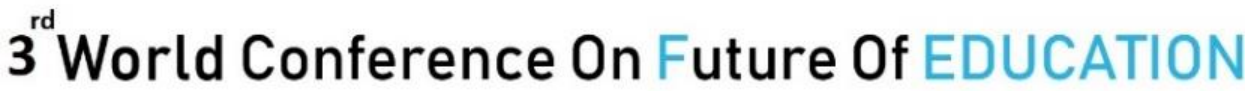

Milan , Italy

7- 9 MAY 2021

\section{Reflections on Geometry Teaching and Learning}

\author{
Nafaa Chbili \\ Department of Mathematical Sciences, College of Science, United Arab Emirates University
}

\begin{abstract}
Geometry is a fundamental branch of mathematics with important applications in many fields of science and engineering. Geometry is taught almost at all levels of curricula, from primary schools where basic shapes and elementary rules of computing areas are introduced to graduate level where the study of the shape of the universe is a cutting-edge research topic. In general, there is no agreement among educators about the most effective teaching approach and considerable amount of research work in mathematics education has been done to address issues related to teaching and learning of geometry. On the other hand, additional challenges to education systems worldwide have been brought with the recent covid-19 outbreak. This led to increasing discussions about teaching methods. Educators are required to adapt their teaching methodologies and strategies to respond to students' need without compromising quality requirements. In this context, project-based learning seems to gain more advocates and gather momentum as this methodology is apparently more appropriate for distance learning. In this paper, we describe how project-based learning had been implemented as a remedial action to certain deficiencies in students' mastery of a learning outcome in an axiomatic geometry undergraduate course. For this purpose, a study had been carried to measure the effectiveness of PBL in comparison to conventional learning. We present some results of course learning outcomes assessments that show an improvement in the level of attainment of a specific course learning outcome as a consequence of the change of instructional methodology from traditional to project-based learning.
\end{abstract}

Keywords: Geometry teaching, project-based learning, learning outcomes 